\title{
Discourse Deficits Following Right Hemisphere Damage in Deaf Signers
}

\author{
Gregory Hickok
}

University of California, Irvine, and Salk Institute for Biological Studies

Margaret Wilson

North Dakota State University

Kevin Clark

Salk Institute for Biological Studies

Edward S. Klima

University of California, San Diego, and Salk Institute for Biological Studies

Mark Kritchevsky

University of California, San Diego, and V.A. Hospital, San Diego

and

Ursula Bellugi

Salk Institute for Biological Studies

Previous findings have demonstrated that hemispheric organization in deaf users of American Sign Language (ASL) parallels that of the hearing population, with the left hemisphere showing dominance for grammatical linguistic functions and the right hemisphere showing specialization for non-linguistic spatial functions. The present study addresses two further questions: first, do extra-grammatical discourse functions in deaf signers show the same right-hemisphere dominance observed for discourse functions in hearing subjects; and second, do discourse functions in ASL

This research was supported in part by NIH grants from the National Institute of Deafness and Other Communication Disorders (R01 DC00201) and from the National Institute of Child Health and Human Development (R37 HD13249). Illustrations copyright Ursula Bellugi, Laboratory for Cognitive Neuroscience, The Salk Institute for Biological Studies, La Jolla, CA. Address reprint requests to Greg Hickok, Department of Cognitive Sciences, University of California, Irvine, CA 92697. E-mail: gshickok@uci.edu. 
that employ spatial relations depend upon more general intact spatial cognitive abilities? We report findings from two right-hemisphere damaged deaf signers, both of whom show disruption of discourse functions in absence of any disruption of grammatical functions. The exact nature of the disruption differs for the two subjects, however. Subject AR shows difficulty in maintaining topical coherence, while SJ shows difficulty in employing spatial discourse devices. Further, the two subjects are equally impaired on non-linguistic spatial tasks, indicating that spared spatial discourse functions can occur even when more general spatial cognition is disrupted. We conclude that, as in the hearing population, discourse functions involve the right hemisphere; that distinct discourse functions can be dissociated from one another in ASL; and that brain organization for linguistic spatial devices is driven by its functional role in language processing, rather than by its surface, spatial characteristics. (c) 1999 Academic Press

Research investigating the neural organization of sign language and spatial cognition in deaf individuals has demonstrated the same hemispheric asymmetries found in hearing individuals: the processing of grammatical aspects of sign language (i.e., individual signs and sentence structure) is predominantly the domain of the left hemisphere, whereas processes involving many aspects of non-linguistic spatial cognition is predominantly the domain of the right hemisphere (Benton \& Tranel, 1993; deRenzi, 1997). Thus, the hemispheric organization of grammatical aspects of language appears to be independent of the modality of that language. This finding is particularly striking given that signed languages such as American Sign Language (ASL) not only take place in space but actually use space and spatial relationships to serve grammatical functions.

As yet, however, there is little evidence on the localization of sign language functions at the extra-grammatical level, in particular, at the level of discourse. In hearing users of spoken language, discourse deficits result from right hemisphere damage (RHD) (Brownell, Potter, Bihrle, \& Gardner, 1986; Wapner, Hamby, \& Gardner, 1981). These deficits involve failures to integrate information across sentences, including impairments in understanding jokes, in making inferences, and in adhering to the storyline when producing a narrative. In contrast, phonological and syntactic processes appear to be intact. This pattern of findings immediately raises two important questions regarding discourse functions in sign language. First, will RHD result in deficits of discourse functions in sign language, as it does for spoken language? Second, do spatial aspects of signed discourse depend on more general spatial ability?

There is preliminary evidence from an RHD hearing subject, who was exposed to ASL in early childhood and became an ASL interpreter, suggesting that a right hemisphere lesion can affect discourse-level processes in ASL (Poizner \& Kegl, 1993), but no data from pre-lingually deaf RHD subjects have been reported. Thus, we cannot be sure whether the data from this subject reflect the brain organization that would characterize individuals whose primary or only language from early childhood onward is ASL. In 
this report we investigate the extent to which RHD affects the processing of signed discourse in two deaf signers, one a native signer of ASL, and one near-native.

\section{The Linguistic Structure of Sign Language}

Signed languages in general evolve naturally from the interactions of deaf people. Like spoken languages, signed languages are highly structured linguistic systems, passed down from one generation to the next. They follow a well-defined developmental course, including a critical period for acquisition (Newport \& Meier, 1985). Signed languages are not based on the spoken language of the surrounding community: ASL and British Sign Language, for example, are mutually incomprehensible, despite the fact that English is the dominant spoken language in both surrounding communities.

All natural human languages have linguistic structure at phonological, morphological, and syntactic levels, and signed languages are no exception. At the phonological level, ${ }^{1}$ signs are composed of meaningless sub-lexical units (handshapes, palm orientations, locations, and movements) which are combined in rule-governed ways (Corina \& Sandler, 1993; Perlmutter, 1992). At the morphological level, ASL has grammatical markers that serve as inflectional and derivational morphemes; these are regular changes in form across classes of lexical items associated with systematic changes in meaning (Klima \& Bellugi, 1979). At the syntactic level, ASL specifies relations among signs using a variety of mechanisms, including sign order, spatial relations among signs, and grammaticized facial expressions (e.g., to mark conditionals) (Liddell, 1980; Lillo-Martin, 1991; Lillo-Martin \& Klima, 1990).

In sum, ASL is an autonomous language with grammatical structuring at the same levels as spoken language and with similar organizational principles. Yet the surface form that this grammatical structuring assumes is radically different. Not only is ASL instantiated in space, and perceived visually, but in addition grammatical distinctions at many levels rely to a large extent on spatial contrasts rather than temporal contrasts. The sublexical units from which signs are composed are often articulated simultaneously rather than sequentially, and spatial location contrasts certain pairs of minimally different signs (Klima \& Bellugi, 1979, Chap. 2); morphological inflections of signs generally alter the movement path of the sign, rather than concatenating morphemic units across time (Klima \& Bellugi, 1979, Chap. 12); and, as we have mentioned, syntactic relations are often specified spatially. Figure 1

${ }^{1}$ Because of the striking structural similarities to the phonology of spoken languages, linguists now use the term "phonology" to refer to the sub-lexical structure of any natural human language, spoken or signed. 


\section{Spatial Contrasts at the Lexical Level}

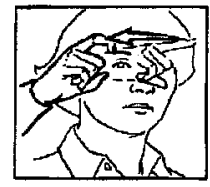

SUMMER

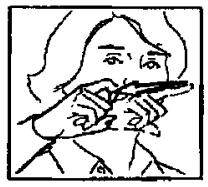

UGLY

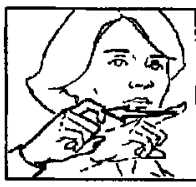

DRY

Spatially Nested Morphology

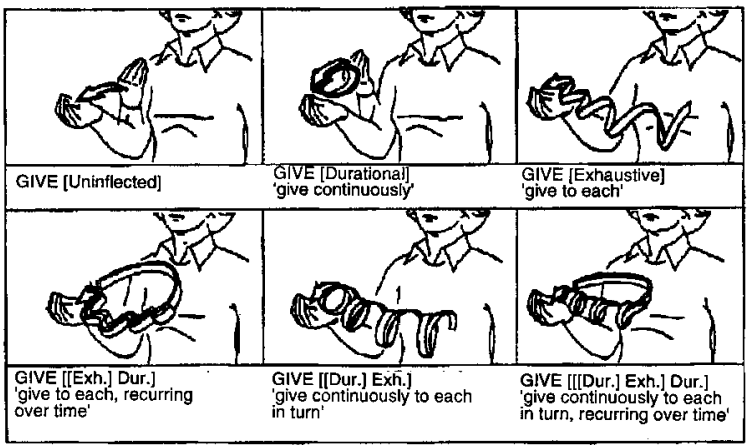

Spatially Organized Syntax

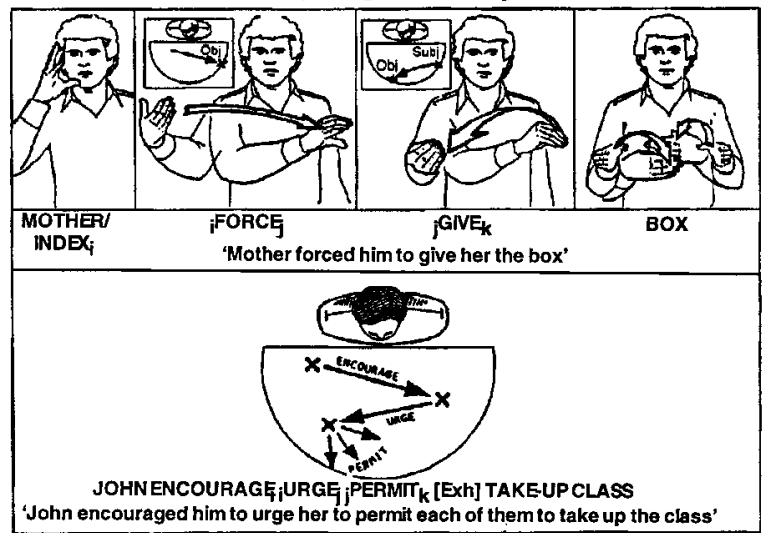

FIG. 1. Linguistic contrasts in ASL involving crucial use of space at the lexical level, the morphological level, and the syntactic level.

shows examples of spatial contrasts at the lexical, morphological, and syntactic levels.

\section{The Brain Organization of Sign Language}

Yet despite this radical difference in surface form, hemispheric localization of ASL grammar appears to be the same as that for spoken language. 
Double-dissociations have been reported between deficits in processing ASL grammar (often seen in LHD signers but not in RHD signers, see Fig. 2A) and deficits in performing non-linguistic visuospatial tasks (often seen in RHD signers and rarely in LHD signers, see Fig. 2B) (Chiarello, Knight, \& Mandel, 1982; Hickok, Klima, Kritchevsky, \& Bellugi, 1995; Hickok, Klima, \& Bellugi, 1996; Poizner \& Kegl, 1993; Poizner, Klima, \& Bellugi, 1987). Note the rating scale profile of sign language characteristics based on the Salk Sign Diagnostic Aphasia Examination for three groups of signers shown in Fig. 2A. The RHD deaf signers are much like the controls, while the LHD deaf signers show a range of different sign language aphasias (Poizner et al., 1987). In contrast, Fig. 2B shows visuospatial abilities in LHD and RHD deaf signers, including drawings to copy of an elephant and a house, a sample block design, and copies of the Rey-Osterreith Complex figure. Note that the left lesioned signers perform well on these non-linguistic visuospatial tasks, while the right lesioned signers exhibit marked deficits involving left neglect, loss of perspective, loss of the overall configuration of the figure, etc. (Hickok et al., 1995; Hickok et al., 1996; Poizner \& Kegl, 1993; Bellugi, Poizner, \& Klima, 1989, 1990; Poizner et al., 1987).

A recent study of a group of 13 LHD signers and 10 RHD signers (Hickok et al., 1996) makes the point quantitatively: the LHD group performed significantly worse than the RHD group on a range of basic language tasks including measures of production, sentence comprehension, naming, repetition, and the ability to make judgments concerning the phonological similarity between signs. An examination of signing ability both in free conversation and in elicited production tasks reveals a range of clinically described aphasic disruptions in LHD signers, but no aphasic deficits in RHD signers. In many respects, the sign aphasias found in LHD signers are similar to those found in hearing patients (Bellugi \& Hickok, 1995).

But while RHD signers do not present with aphasia for sign at the lexical, morphological, or syntactic level, they do show significant deficits in nonlinguistic visuospatial processing (Bellugi \& Hickok, 1995; Hickok et al., 1996; Poizner et al., 1987). Their drawings and figure-copying production are often fragmented, without perspective, and often show evidence of hemispatial neglect. In contrast, aphasic LHD signers often perform normally on these non-linguistic spatial-cognitive tasks. Apparently, the ability to process a spatially organized language and the ability to carry out non-linguistic visuospatial tasks are subserved by different neural systems.

\section{Spatialized Discourse Structure in Sign Language}

As noted above, spatial contrasts are used at every level of grammatical structure of signed languages. But space also serves a function at the extrasyntactic discourse level: discourse referents are established at distinct posi- 

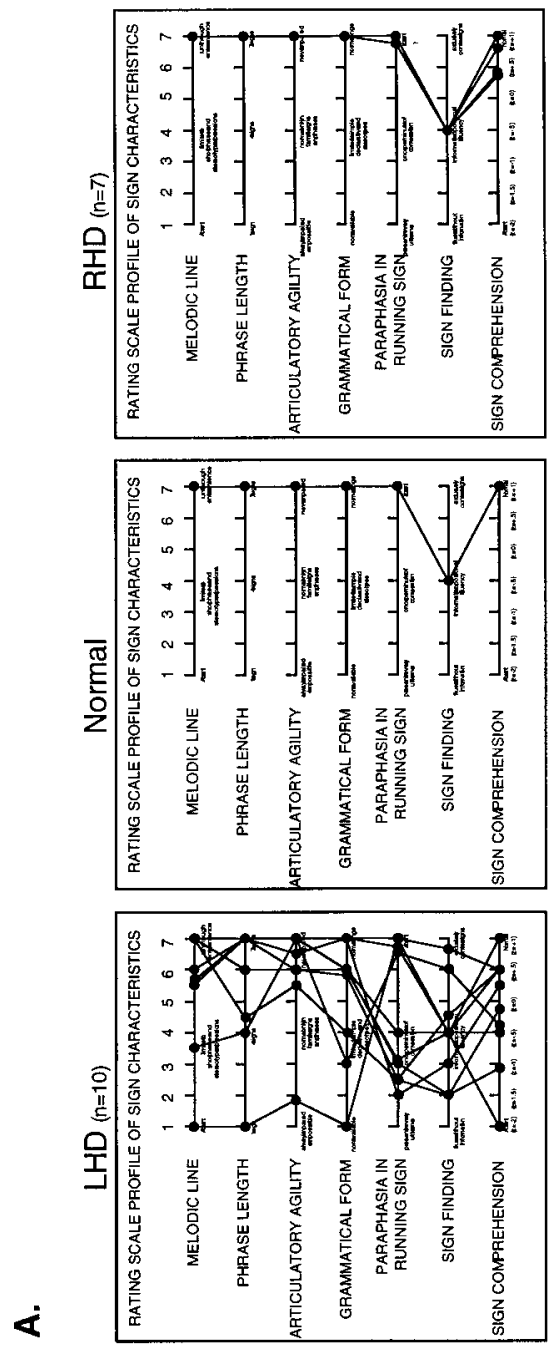

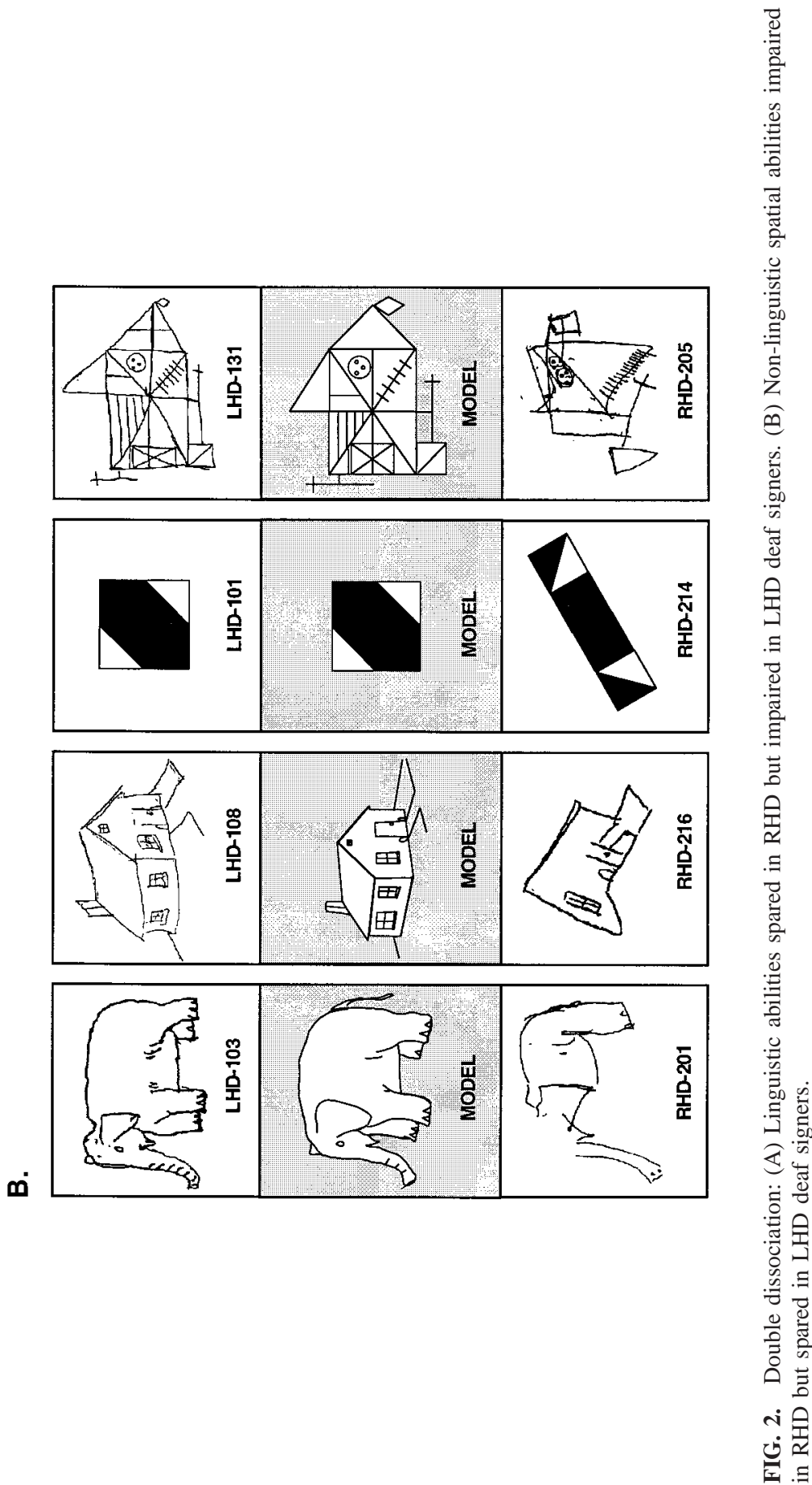

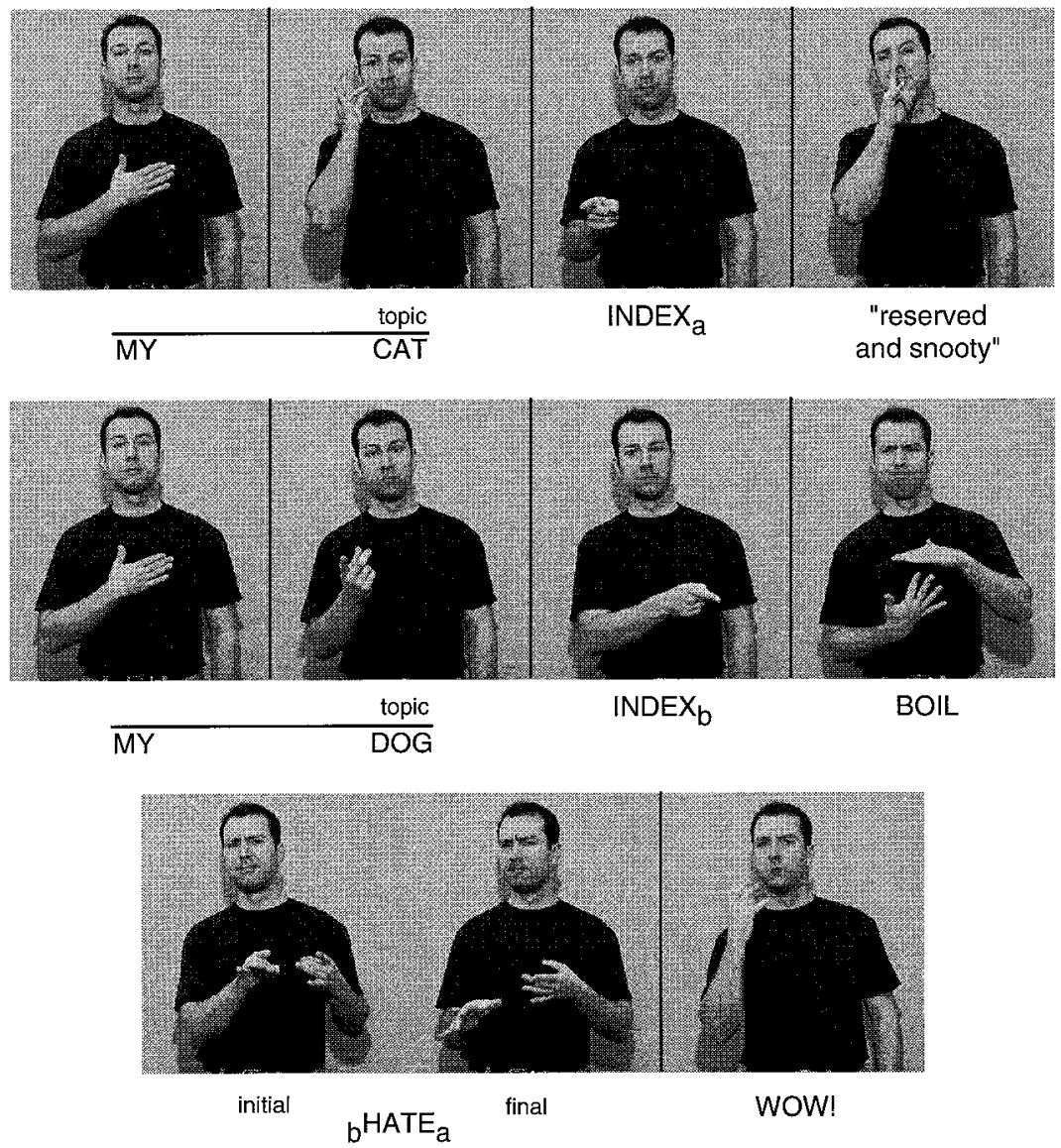

English Translation:

"My cat is reserved and snooty, and my dog is boiling mad. He (the dog) really hates him (the cat), wow!"

FIG. 3. Example of spatially organized discourse in ASL.

tions in signing space, providing a spatially organized "referential framework" through which the discourse takes place. In order to produce a connected discourse, the signer must maintain consistency in this spatial referential framework from one sentence to the next. In addition, through various discourse-specific mechanisms (e.g., body shift, eye gaze, and crosssentential pronominal reference) the signer can manipulate the spatial referential framework to mark shifts in discourse focus, to assume the role and perspective of a given character in the discourse, and to mark semantic roles (Bahan \& Petitto, 1980; Engberg-Pedersen, 1993; Padden, 1986). Figure 3 
presents an example of spatially organized discourse in ASL using cross sentential pronominal reference and consistency of spatial referential framework (Emmorey \& Lillo-Martin, 1995).

Since these kinds of discourse functions require the ability to keep track of spatial locations and relationships, one might hypothesize that disruptions in general spatial cognitive ability should lead to deficits in the ability to produce a referentially coherent discourse. We now investigate the hemispheric organization of these spatial aspects of ASL, and their relationship to general spatial abilities, as well as non-spatial discourse abilities.

\section{Two Case Studies of Deaf RHD Signers: AR and SJ}

$\mathrm{AR}$ is a right-handed man who was deaf from birth and acquired ASL in a residential school for the deaf at age 6. At the age of 72 he suffered a large right hemisphere ischemic infarct in the territory of the middle cerebral artery. A T1-weighted MR scan (3-D volume SPGR, slice thickness $=1.5$ $\mathrm{mm}$ ) was acquired two years post-stroke. Surface reconstruction using Brainvox software (Damasio \& Frank, 1992) showed that the lesion involved the length of the right superior and middle temporal gyri, the angular and supramarginal gyri, and inferior area 7-with deep subcortical extension. Age at testing was 74, two years post-stroke. Administration of our ASL-adapted version of the Boston Diagnostic Aphasia Examination revealed AR's sign production to be fluent, grammatical, and phonologically intact (see Fig. 4B), and his comprehension was good.

$\mathrm{SJ}$ is a right-handed deaf man who was born deaf to deaf parents and thus acquired ASL from birth. At the age of 66 he suffered a large right hemisphere ischemic infarct in the distribution of the middle cerebral artery. A T1-weighted MR scan (3-D volume SPGR, slice thickness $=1.5 \mathrm{~mm}$ ) was acquired nine years post-stroke. Surface reconstruction (Damasio \& Frank, 1992) showed that the lesion involved cortex in the immediate perisylvian area of the right hemisphere and extended subcortically over a large region in the frontal, parietal, and temporal lobes. Age at testing was 75, nine years post-stroke. Like AR, SJ performed well on the BDAE with fluent, grammatical, and phonologically intact sign production and good comprehension (see Fig. 4C).

Both subjects' signing was flawless at the single sign and within-sentence level; there was no evidence of aphasia. In casual conversation, however, it was readily apparent that both had deficits involving the production of connected discourse, but each in a different way. AR had extreme difficulty sticking to the topic of a conversation or narrative. Despite this, he had no difficulty maintaining consistency of spatial referents for discourse purposes, and was fully capable of manipulating referetial space to mark changes in perspective and other discourse-level shifts. In contrast to AR, SJ had no trouble carrying on a discourse without digressions. However, we did note 


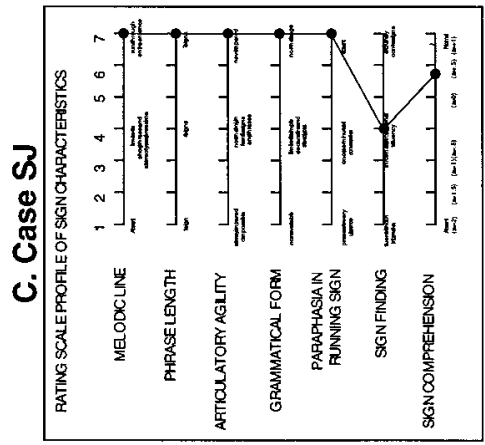

重
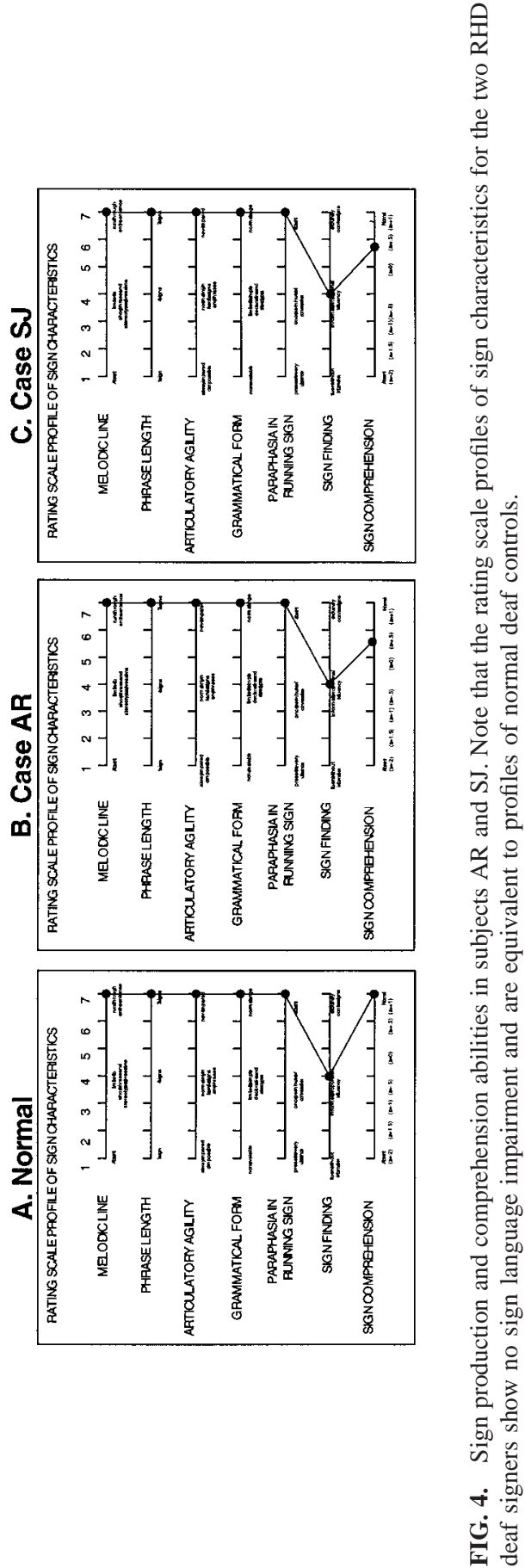
a near complete absence of mechanisms used to manipulate the spatial referential discourse framework, and frequent failures in maintaining consistent spatial loci for discourse referents. This often made SJ's discourse vague or ambiguous with respect to referents in the discourse.

\section{EXPERIMENT 1}

In order to further explore AR and SJ's discourse abilities, the subjects were presented with a sequence of pictures which represented a story and were asked to produce a narrative describing the sequence of action. The story, which involved physical interaction among characters, was designed to elicit a range of spatialized discourse referential mechanisms (see Fig. 5). Subjects' narrations were videotaped, and the videotapes were analyzed by a deaf native signer of ASL. This analysis included, first, tabulation of the number of confabulatory or tangential utterances-defined as sentences whose content failed to relate to that of the previous sentence, or which included content not present in the pictorial story-and calculation of the ratio of such tangential utterances to the total number of utterances. Second, the analysis included tabulation of the number of errors in spatially organized discourse, defined as failure to maintain consistency of previously established spatial references, or ambiguity of content resulting from a failure to appropriately use spatial devices.

\section{Tangential Utterances}

Sixty percent of AR's utterances were tangential to the story. A large proportion of these tangential utterances were unrelated to the story, and frequently involved abrupt shifts in topic. When his attention was successfully redirected to the story by the experimenter, AR's utterances included confabulatory information, introducing characters and actions that did not occur in the picture sequence. In contrast, SJ produced no tangential utterances (see Fig. 6).

\section{Errors in Spatially Organized Discourse}

AR made only one spatial discourse error (see Fig. 6). This paucity of errors cannot be explained in terms of an absence of spatial devices, as AR did in fact make frequent and appropriate use of such devices. To the extent that AR remained on-topic across sentences, he maintained the consistency of spatial devices across those sentences. In contrast, SJ made 15 spatial discourse errors, including (a) failure to maintain discourse referents in their initially established locations, (b) failure to maintain consistent planes of reference (he initially set up referents in the "sagittal" plane and then switched to the "axial" plane; he then switched back and forth several times), and (c) failure to use body shift to mark the discourse topic in situa- 

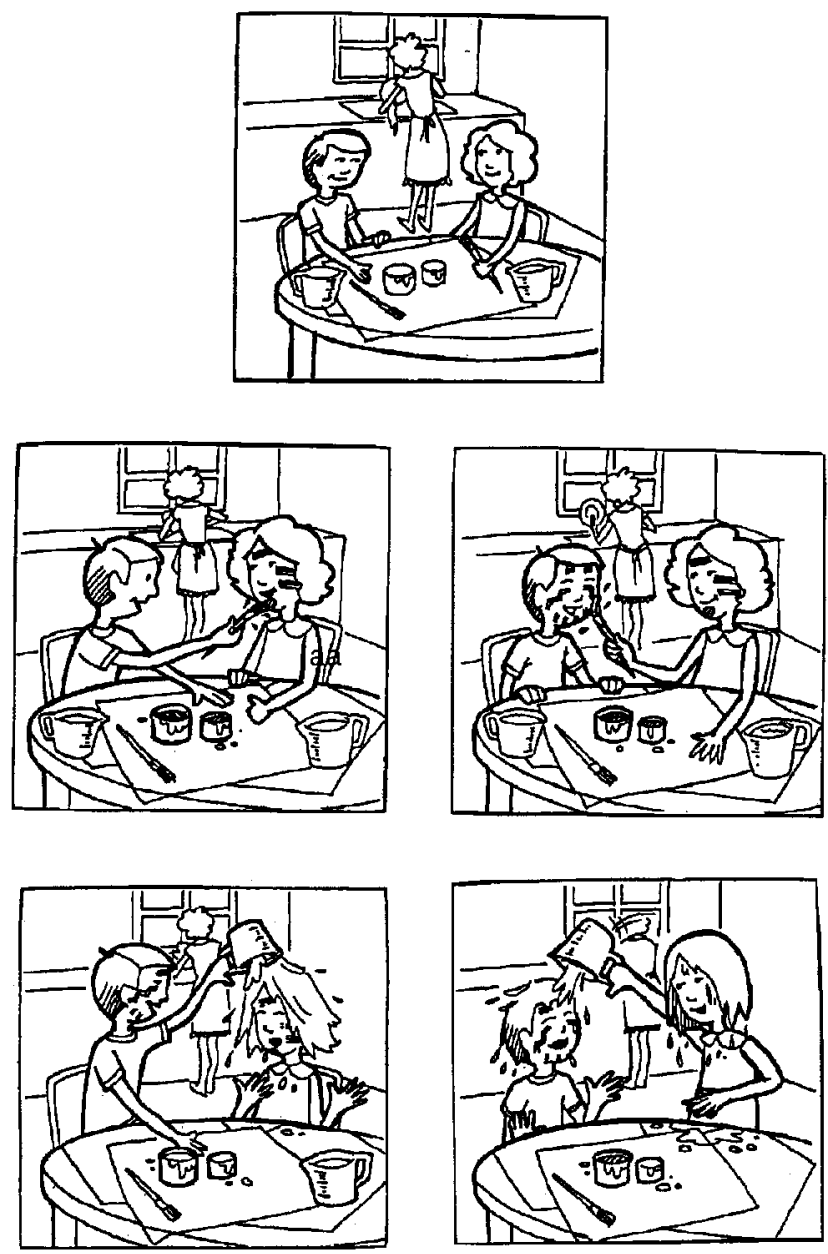

FIG. 5. Sample pictures from "Paint Story," a wordless picture sequence designed to elicit spatialized discourse mechanisms of ASL.

tions that demanded such a marker. See Fig. 7 for examples of SJ's spatialized discourse errors.

This double dissociation between errors of topical coherence and errors of spatial referential devices indicates two separate components of discourse processes in ASL, both of which appear to involve the right hemisphere.

\section{EXPERIMENT 2}

To what extent is spatialized discourse dependent on non-linguistic spatial abilities? To address this question, we administered a set of standard spatial 


\section{Discourse Deficits in RHD Deaf Signers}

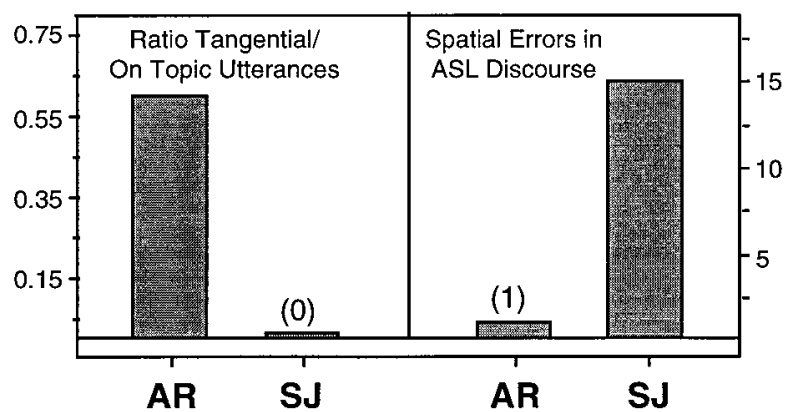

FIG. 6. Contrasting types of discourse errors in the two RHD deaf signers: Tangential utterances are very frequent in AR (60\% of utterances) but essentially absent in SJ (left) and spatial errors in ASL discourse mechanisms are minimal in AR but rampant in SJ (right).

cognitive tests to both subjects including (i) BDAE drawing tasks, (ii) the WAIS-R Block Design Test, (iii) the Rey-Osterrieth Complex Figure Test, and (iv) Albert's Neglect Test. Both SJ and AR performed very poorly on these tests of visuospatial abilities. As can be seen in Fig. 8, their drawings were fragmented and lacked perspective, they frequently failed to reproduce the global configuration in the Block Design task, and both showed evidence of neglect. Given that only SJ had a deficit in spatial aspects of discourse, while AR performed normally in this respect, it appears that deficits in these spatial cognitive abilities are not a necessary condition for deficits in spatialized discourse.

\section{CONCLUSIONS}

Our findings to date show that RHD does not impair sign language processing at the grammatical level, and the present cases are no exception. However, RHD can disrupt processing at the discourse level-that is, at the level of cross-sentence integration and organization.

These results suggest, first, that the right hemisphere is involved in discourse processing in ASL, as it is in spoken language; and second, that there are dissociable subcomponents of discourse processing in ASL. The first is an ability to maintain topical cohesion, and its disruption results in "tangential speech" similar to that observed in hearing RHD patients (Brownell et al., 1986). The second is the ability to consistently use and maintain spatialized discourse functions. This aspect of discourse processing may be unique to users of signed languages. Alternatively, it may prove to be an analog to certain referential functions in spoken language such as pronomial reference and the ability to maintain connections between pronouns and their referents. Finally, given that both patients were severely impaired on non- 


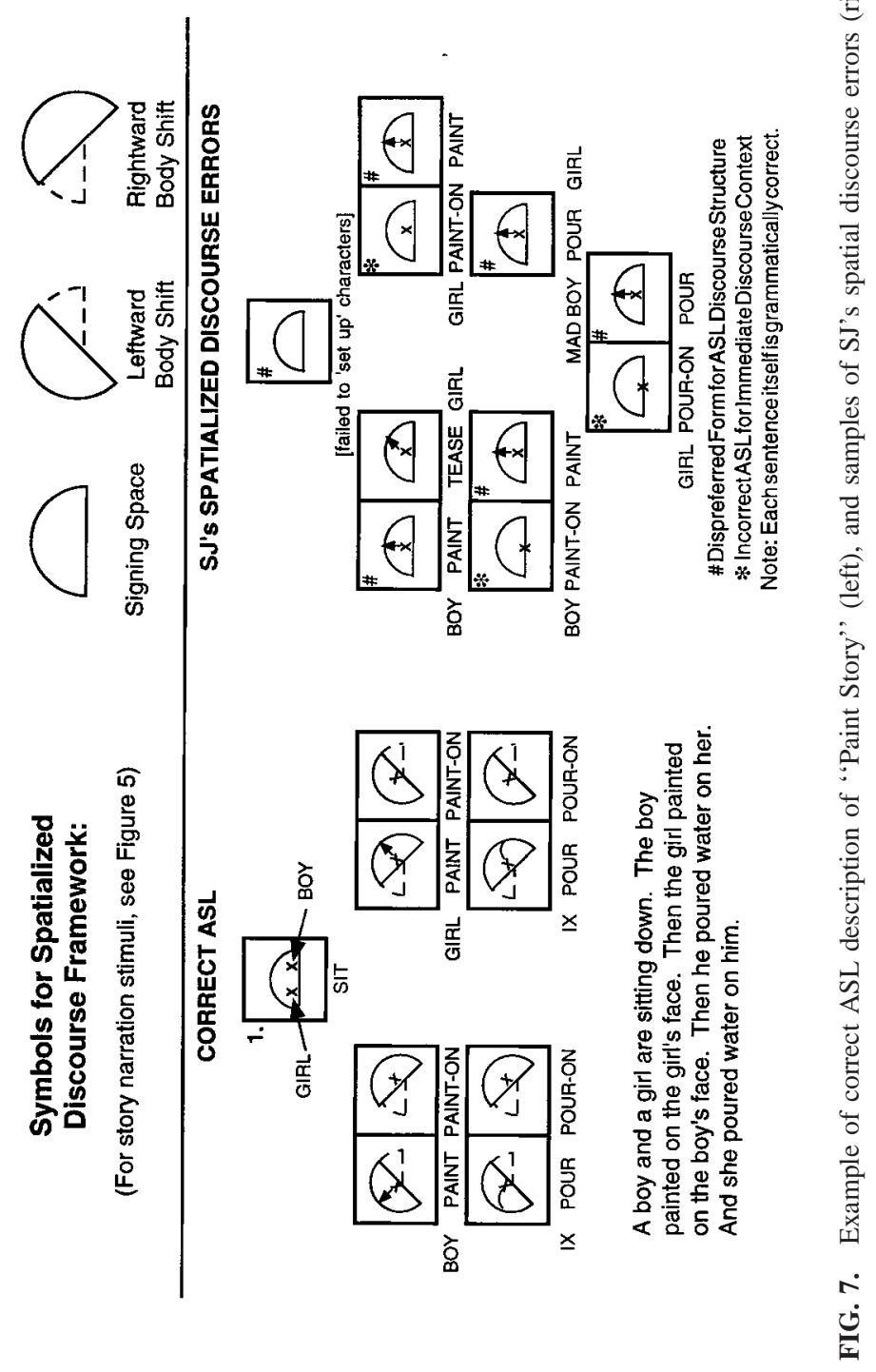



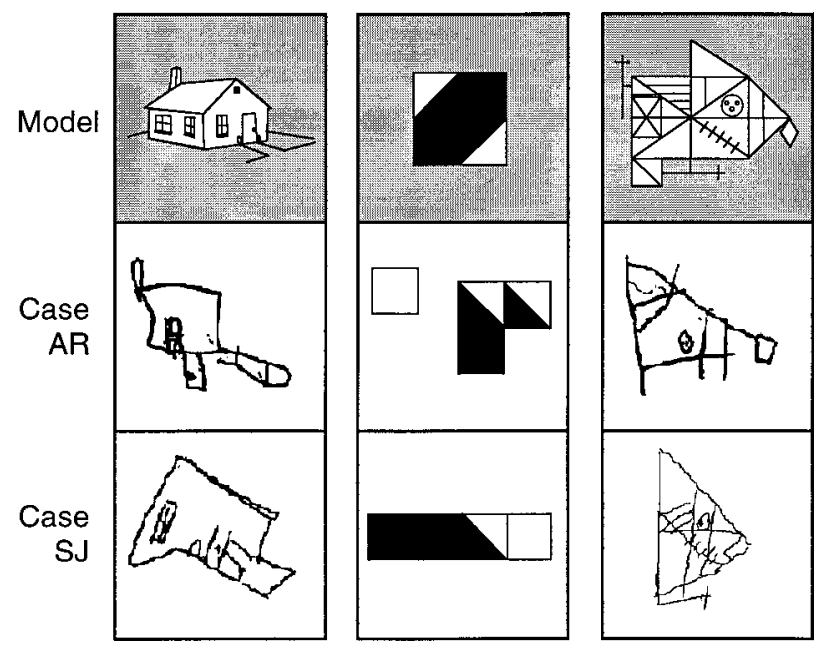

FIG. 8. Samples of AR and SJ's drawings and block designs, showing deficits in spatial processing in both RHD deaf subjects.

linguistic visuospatial tasks, and yet differed with respect to their discourse deficit, impaired spatialized discourse apparently is not simply a secondary effect of severe spatial cognitive disruption.

The present result parallels the earlier finding that processing spatially encoded grammatical information in ASL is independent of non-linguistic spatial cognition (Hickok et al., 1996). The general notion "visuospatial processing" thus appears to have little predictive power with respect to neural organization: processing spatial information as it is used in grammatical encoding, in discourse encoding, and in non-linguistic spatial domains all appear to be functionally independent. These results suggest that at least some aspects of brain organization are driven by the functional domains of information processing, independently of how that information is encoded.

\section{REFERENCES}

Bahan, B., \& Petitto, L. 1980. Aspects of rules for character establishment and reference in ASL storytelling. Unpublished manuscript, The Salk Institute for Biological Studies.

Bellugi, U., \& Hickok, G. 1995. Clues to the neurobiology of language. In R. Broadwell (Ed.), Decade of the brain (Vol. 1, pp. 87-107). Washington, DC: Library of Congress.

Bellugi, U., Poizner, H., \& Klima, E. S. 1990. Mapping brain functions for language: Evidence from sign language. In G. M. Edelman, W. E. Gall, \& W. M. Cowan (Eds.), Signal and sense: Local and global order in perceptual maps (pp. 521-543). New York: WileyLiss.

Bellugi, U., Poizner, H., \& Klima, E. S. 1989. Language, modality and the brain. Trends in Neurosciences, 10, 380-388.

Benton, A., \& Tranel, D. 1993. Visuoperceptual, visuospatial, and visuoconstructive disorders. 
In K. M. Neilman \& E. Valenstein (Eds.), Clinical neuropsychology (3rd ed. pp. 165213). Oxford: Oxford Univ. Press.

Brownell, H. H., Potter, H. H., Bihrle, A. M., \& Gardner, H. 1986. Inference deficits in right brain-damaged patients. Brain and Language, 27, 310-321.

Chiarello, C., Knight, R., \& Mandel, M. 1982. Aphasia in a prelingually deaf woman. Brain, 105, 29-51.

Corina, D., \& Sandler, W. 1993. On the nature of phonological structure in sign language. Phonology, 10, 165-207.

Damasio, H., \& Frank, R. 1992. Three-dimensional in vivo mapping of brain lesions in humans. Archives of Neurology, 49, 137-143.

deRenzi, E. 1997. Visuospatial and constructional disorders. In T. E. Feinberg \& M. J. Farah (Eds.), Behavioral neurology and neuropsychology (pp. 297-307). New York: McGrawHill.

Emmorey, K., \& Lillo-Martin, D. 1995. Processing spatial anaphora: Referent reactivation with overt and null pronouns in American Sign Language. Language and Cognitive Process, 10, 631-653.

Engberg-Pedersen, E. 1993. Space in Danish Sign Language: The semantics and morphosyntax of the use of space in a visual language. Hamburg: Signum-Verlag.

Hickok, G., Klima, E., Kritchevsky, M., \& Bellugi, U. 1995. A case of "sign blindness" following left occipital damage in a deaf signer. Neuropsychologia, 33, 1597-1606.

Hickok, G., Klima, E. S., \& Bellugi, U. 1996. The neurobiology of signed language and its implications for the neural basis of language. Nature, 381, 699-702.

Klima, E., \& Bellugi, U. 1979. The signs of language. Cambridge, MA: Harvard Univ. Press. Liddell, S. 1980. American Sign Language syntax. New York: Mouton.

Lillo-Martin, D. 1991. Universal grammar and American Sign Language: Setting the null argument parameters. Boston: Kluwer Academic.

Lillo-Martin, D., \& Klima, E. S. 1990. Pointing out differences: ASL pronouns in syntactic theory. In S. D. Fischer \& P. Siple (Eds.), Theoretical issues in sign language research: Vol. 1. Linguistics (pp. 191-210). Chicago, IL: Univ. of Chicago Press.

Newport, E., \& Meier, R. 1985. The acquisition of American Sign Language. In D. I. Slobin (Ed.), The crosslinguistic study of language acquisition: Vol. 1. The data. Hillsdale, NJ: LEA.

Padden, C. A. 1986. Verbs and role-shifting in ASL. In C. Padden (Ed.), Proceedings of the Fourth National Symposium on Sign Language Research and Teaching (pp. 44-57). Silver Spring, MD: National Association of the Deaf.

Perlmutter, D. M. 1992. Sonority and syllable structure in American Sign Language. Linguistic Inquiry, 23, 407-442.

Poizner, H., \& Kegl, J. 1993. Neural disorders of the linguistic use of space and movement. Annals of the New York Academy of Sciences, 682, 192-213.

Poizner, H., Klima, E. S., \& Bellugi, U. 1987. What the hands reveal about the brain. Cambridge, MA: MIT Press.

Wapner, W., Hamby, S., \& Gardner, H. 1981. The role of the right hemisphere in the apprehension of complex linguistic materials. Brain and Language, 14, 15-33. 